\title{
eHRM: An Empirical Study on Employee Perception and Satisfaction
}

\author{
Abdul Kadar Muhammad Masum ${ }^{1 *}$ Abdullah Md. Ahshanul Mamun ${ }^{2}$ \\ ${ }^{1}$ Department of Computer Science and Engineering, International Islamic University Chittagong, \\ Chittagong, Bangladesh \\ ${ }^{2}$ Department of Business Administration, International Islamic University Chittagong, Chittagong, \\ Bangladesh \\ * E-mail of the corresponding author: akmmasum@yahoo.com
}

\begin{abstract}
The prime concern of this research is to investigate the rapport between human resource (HR) professional's perception towards electronic human resource management (eHRM) and their satisfaction for eHRM usage. Data were obtained from $180 \mathrm{HR}$ professionals in banking industry of Bangladesh using purposive sampling technique. For data analysis, one-way ANOVA test along with other correlation techniques are exercised as statistical tools. Results indicate that software quality, perceived usability, perceived usefulness, and user support have a strong association with user satisfaction that is developed from eHRM usage. The research explores a positive rapport between HR personnel's satisfaction for eHRM usage and HR personnel's perceptions towards eHRM. Moreover, the study reveals that the demographic variables (gender, age, educational level, etc) have no influence on perception towards and eHRM satisfaction. The findings of the study will be helpful for the HR managers to take necessary steps to grab the maximum benefits of eHRM usage.
\end{abstract}

Keywords: Electronic human resource management (eHRM); perceived usefulness; perceived usability; software quality; user satisfaction; user support

DOI: $10.7176 / \mathrm{JIEA} / 11-2-06$

Publication date: June $30^{\text {th }} 2021$

\section{Introduction}

Currently, human resource (HR) professionals are more reliant on information systems (ISs) to perform HR activities efficiently and effectively due to tremendous advancement of information technology (IT) (Masum et al., 2015). Realizing the immense features and benefits, they move from traditional human resource management (HRM) to eHRM (Masum, 2015). Researchers attested that an eHRM automates HR services in the HR department.it delivers efficient HRM facilities for the entire organization (Strohmeier, 2009), thus eHRM becomes a strategic actor within the organization (Ibrahim and Yusoff, 2015).

The HR work routines, activities, personnel's competencies and capabilities are changed as well during the conversion of HR from managerial expert to tactical partner. Therefore, two vital issues are arisen: whether HR personnel will receive these modifications and whether the company will face any accidental consequence (Wiblen et al., 2010). The contemporary research stated that strategic transformation of HR department may introduce some unanticipated consequences for HR department especially for individual HR personnel in the HR department.

Nowadays, eHRM study is in the initial phase for the organizations of Bangladesh (Masum et al., 2020). As far our knowledge goes, there is no research on employee perception and their satisfaction with eHRM usage in context of Bangladesh. Thus, there is scarcity of research for finding the factors of HR personnel's perception and their satisfaction for eHRM usage (Alam et al., 2016). The prime aim of the study is to define the relationship between HR personnel's satisfaction for eHRM and HR personnel's perceptions towards eHRM. Also, it is intended to expose that whether the demographic variables i.e. gender, age, etc. have any effect on perception towards and eHRM satisfaction.

\section{Background of the study and related works}

\subsection{Electronic human resource management (eHRM)}

eHRM is considered as an umbrella term (Bondarouk \& Ruël, 2009). It is used to indicate all probable combination mechanisms and contents within the IT and HRM department. It is expected at creating value within and across companies for the HR manager and selected employees (Stone et al., 2015). Masum et al. (2013) agreed that eHRM 
pays considerably to the different HR functions such as payroll,, administration and pension sharing shared database to all HR related units. Subsequently, the HR section becomes a tactical business partner after employing the eHRM (Wright, 2008). Researchers have recently stated that eHRM is interchangeably used as web-based HRM, human resource information system (HRIS), and Intranet-based HRM (Masum, Beh, Azad \& Hoque, 2018).

\subsection{HR personnel's attitude for eHRM}

After implementation of eHRM, each person evaluates the newly implemented technology in terms of its simplicity of use and usefulness (Maier et al., 2013). One of the crucial success factors of eHRM implementation is HR personnel's operating skills of the new software (Lukaszewski et al., 2008). The past study indicates that organization will fail to realize the benefits of eHRM if HR personnel do not have knowledge and expertise to use the eHRM (Panayotopoulou et al., 2007). The shortage of expertise and knowledge confine HR personnel to explore the full potential benefits of an eHRM. Moreover, HR personnel may perceive the eHRM usage negatively, when they are unaware of all the potentials of an eHRM system. On the other hand, HR personnel who perceive the system as a facilitator for their work and strategic weapon for the organization they consider the eHRM as more useful.

In an organization, eHRM implementation may be considered a stress event when employees perceive the change situation negatively (Lukaszewski et al., 2008). The eHRM implementation causes HR personnel to review their states at work (Vandenberghe et al., 2011). For example, HR personnel may perceive that they will fire after eHRM implementation owing to condensed demand for staff related with supervision rather than managerial tasks (Panayotopoulou et al., 2007).

According to Masum et al. (2020), there is a perceptual belief: HR personnel's perceived usability and perceptions of usefulness are linked to eHRM usage. So, this perceptual belief affects the attitude of HR personnel toward the eHRM usage. Furthermore, if HR personnel have sufficient skills and knowledge to eHRM usage, they evaluate an EHRM as positive. Therefore, extra work through training is essential to ensure the positive evaluation of HR personnel. Moreover, HR personnel develop a negative attitude towards eHRM usage if the system is challenging to use (Bondarouk and Ruël, 2009). About usefulness, HR personnel believe an eHRM to improvement the efficiency of HR activities (Lukaszewski et al., 2008), contribution in extensive variety of HRM decisions (Beckers and Bsat, 2002), automate managerial HR activities (Ngai et al., 2008) so that eHRM usage increases HR personnel standing with eHRM (Lawler and Mohrman, 2003). Moreover, Maier et al. (2013) stated that eHRM implementation has an intense effect on job satisfaction and intention to quit of HR personnel.

Based on above discussion, HR employee's role and his work routines are changed for implementation of eHRM in the organizations. The newly implemented eHRM is considered as negative approach when an employee does not like organizational changes that are occurred for eHRM. On the other hand, when an employee likes organizational changes that are occurred for eHRM he appreciates the eHRM implementation. Therefore, there is a possibility of decreasing or increasing of HR staffs job satisfaction and intention to quit the job.

\subsection{HR professionals' satisfaction with the eHRM}

Examination about technology adoption uses very much upheld hypotheses and structures clarifying an individual's IT innovation utilization (Ashraf et al., 2019). These can be valuable in becoming acquainted with the effects of an eHRM execution for both the existing and potential users of the software. Such investigation is usually performed on the TAM theory (Technology Adoption Model) and gives experimental proof highlighting individual's convictions and mentality toward the utilization of a software that impacts their expectations in utilizing the system and likewise their use behavior (Davis, 1989). A few investigations have evaluated and thought this relationship. Nonetheless, not all analysts agreed that the attitude and perception towards utilizing the software can foresee the conduct of HR staff's utilization in associations, especially when organizations command that their workers utilize new software (Masum, Mamun,, Islam, and Beh, 2020). At the point when associations are executing new technology or software demanding their utilization, workers will be compelled to utilize them, regardless of whether they hold negative mentalities and convictions towards the technology or software. It then, at that point follows that an individual's demeanor to the utilization of a newly implemented software may not be basically identified with the behavioral aim to utilizing it and the subsequent use behavioral (Brown et al., 2002).

\section{Research methodology}


The comprehensive research methods and techniques for data collection, variable measurement, data analysis to achieve the objectives of the study are discussed in this section.

\subsection{Sample and data collection}

Two hundred HR professionals (HR executives, HR manager, HR officers) from 36 private banks participated to the study. The usable questionnaires were 180. The survey was conducted during September 2019 to November 2019. In this study, purposive sampling technique was used to select suitable people for the sample as there are few organizations in Bangladesh that are using eHRM.

\subsection{Measure}

The developed questionnaire consists of three sections. First part comprises demographic credentials such as gender, age, education, work experience and their organizational position. For measurement instrument of the research, two scales were adopted. In first scale, software quality, usefulness, usability, and user support of eHRM applications were measured adopting 19 items. Among the four measurements, eight items were used to assess software quality that was adapted from past studies (Doll \& Torkzadeh, 1988 and Davis, 1989). Five items were used to assess perceived usability that was adapted from Davis (1989); 4 items were employed to assess perceived usefulness was adapted from (Davis, 1989); and 2 items were used to assess user support that was adapted from Voermans and Veldhoven, (2007). In second scale, 3 items were used to measure user satisfaction for eHRM (Armstrong et al., 2005; Lin \& Lee, 2006; and Wang, 2008). All the scale items in this study were revised in the eHRM setting.

\subsection{Data analysis}

Five-point Likert-type scale was for user (HR personnel) satisfaction and perception towards of HR personnel. The scale indicates " 1 : strongly disagree" to " 5 : strongly agree". Parametric tests were adopted in this study. Initially, the normality of data was achieved by Kolmogorov-Smirnov test. The results showed that data was normally distributed. First, descriptive statistics was used to represent demographic data of respondents. Second, mean, standard deviation, and reliability test were used for research instrument validity. To examine the association between perception towards eHRM and user satisfaction for eHRM, Pearson correlation test was employed. Finally, to define the differences along with demographic qualifications, one-way ANOVA test and t-test were used. SPSS for Windows 20.0 package program was adopted for data analysis.

\subsection{Hypotheses of the Study}

In this paper, the association between HR personnel's satisfaction for eHRM and HR personnel's perceptions of eHRM are examined. Also, it is tested whether or not these two variables (HR personnel's satisfaction and HR personnel's perceptions) vary along with demographic variables such as gender, age and position.

The prime hypotheses of this study are highlighted below:

H1: There is a link between HR personnel's satisfaction for eHRM and HR personnel's perceptions towards eHRM.

H1a: HR personnel's perceptions towards eHRM show difference along with their job position.

H1b: HR personnel's satisfaction for eHRM shows difference along with their job position.

H1c: HR personnel's perceptions towards eHRM show difference along with their genders.

H1d: HR personnel's satisfaction for eHRM shows difference along with their genders.

H1e: HR personnel's perceptions towards eHRM show difference along with their education levels.

H1f: HR personnel's satisfaction for eHRM shows difference along with their education levels.

H1g: HR personnel's perceptions towards eHRM show difference along with their ages.

H1h: HR personnel's satisfaction for eHRM shows difference along with their ages.

\section{Findings and results}

To find the reliability of the measurement variables, Cronbach's alpha coefficients were calculated. The reliability values of perception towards eHRM and satisfaction for eHRM are 0.921 and 0.815 respectively. Hence, the results demonstrate that both of scales are internally consistent and reliable in social sciences (Gliem and Gliem, 2003).

HR professionals form private banking sector participated to the research $(n=180)$. Table 1 demonstrates a total of 112 males (62.22\%) and 68 females (37.78\%) completed and returned the questionnaires. The participating HR 
professionals ranged in age from 25 to 60 years, of whom 34 people (18.89\%) are between $25-30 ; 65$ people (36.11\%) are between $32-36 ; 45$ people (25\%) are between $37-42$ and 36 people $(20 \%)$ are more than the age of 43. The average age of the respondents was 37.56 years. Further, $16.11 \%$ of the participants (29 people) had a Bachelor's degree, $81.11 \%$ (146 people) had a Master's degree, and 2.78\% (5 people) had an M.Phil degree among the HR professionals. Concerning their present position in the firm, 78 people $(43.33 \%)$ were low-level HR officers, 62 people (34.45\%) were mid-level HR manager, and 40 people $(22.22 \%)$ were top-level HR managers. The work experience of respondents was 6.25 years in average with the organizations.

The descriptive statistics shows that the mean for perception of HR personnel to the e-HRM use scale was figured as 3.78 (SD: 0.73) and the mean for HR satisfaction for eHRM fulfillment scale was calculated as 3.69 (SD: 0.69). The standard deviation and mean values for each variable were described in table 2 . All variables recorded moderate scores. In table 2, the results show that the respondents provided responses to the two scales as "agree". In perception towards scale, 4 elements of the scale are assessed near one another and respondents see eHRM related work nearly with a similar significance. Similarly, the mean of the dimensions of user Satisfaction for eHRM scale was calculated as 3.69 (SD: 0.69). Here, it is observed that the respondents highlighted the significance of eHRM, and simultaneously they are satisfied with the eHRM software. So, hypothesis H1 is accepted.

Table: 1: Demographic information of respondents

\begin{tabular}{cccc}
\hline Name of Variables & Particular & Frequency & (Percentage) \\
\hline \multirow{2}{*}{ Gender } & Female & 68 & 37.78 \\
& Male & 112 & 62.22 \\
\hline \multirow{3}{*}{ Age } & $25-30$ & 34 & 18.89 \\
& $31-36$ & 65 & 36.11 \\
& $37-42$ & 45 & 25 \\
Education & 43 and more & 36 & 20 \\
\hline \multirow{3}{*}{ Position } & Undergraduate & 29 & 16.11 \\
& Graduate & 146 & 81.11 \\
& MPhil/ Ph.D & 5 & 2.78 \\
\hline \multirow{3}{*}{ Experience } & Top-level HR managers & 40 & 22.22 \\
& Mid-level HR manager & 62 & 34.45 \\
& Low-level HR officers & 78 & 43.33 \\
\hline & Less than 1 & 32 & 17.78 \\
& $1-3$ year & 42 & 23.33 \\
& $4-6$ year & 47 & 26.11 \\
& 7-9 year & 33 & 18.33 \\
& 10 and more & 26 & 14.45 \\
\hline
\end{tabular}

To test the association between HR personnel's satisfaction for eHRM and HR personnel's perceptions of eHRM, Pearson correlation analysis was applied. In line with the results, a positive and very strong relationship was found between HR personnel's satisfaction for eHRM and HR personnel's perceptions of eHRM. And, the correlation value is $0.857(\mathrm{p}<0.01)$. So, $\mathrm{H} 1$ hypothesis is accepted. 
Table 2.Mean, Standard Deviation values of the dimensions and scales

\begin{tabular}{cccc}
\hline Scale and Dimension & Mean & SD & N \\
\hline Software quality & 3.82 & .71 & 180 \\
\hline Perceived usefulness & 3.76 & .79 & 180 \\
\hline Perceived usability & 3.85 & .68 & 180 \\
\hline User support & 3.61 & .72 & 180 \\
\hline Perception towards (total) & 3.78 & .73 & 180 \\
\hline User satisfaction for eHRM & 3.69 & .69 & 180 \\
\hline
\end{tabular}

In table 3, likewise, the connection between eHRM measurements of perception and user satisfaction from eHRM was examined to understand this positive association better. A correlation examination was performed between each of the variables and user satisfaction from eHRM to detect the significant influence of the construct. The results also indicate that software quality has a positive correlation with user satisfaction $(\mathrm{r}=0.588, \mathrm{p}<0.01)$. Consistently with perceived usefulness has positive correlation with user satisfaction $(r=0.666, p<0.01)$. Similarly, perceived usability has positive correlation with user satisfaction $(\mathrm{r}=0.588, \mathrm{p}<0.01)$. Additionally, user support was positively related to user satisfaction $(\mathrm{r}=0.452, \mathrm{p}<0.01)$. As expected, facilitating conditions was also correlated with user satisfaction $(\mathrm{r}=0.452, \mathrm{p}<0.01)$.

Table 3: Correlation between perception towards dimensions and user satisfaction for eHRM

\begin{tabular}{|c|c|c|c|c|c|}
\hline Variables & 1 & 2 & 3 & 4 & 5 \\
\hline 1.Software quality & 1 & & & & \\
\hline 2.Perceived usefulness & $.773 * *$ & 1 & & & \\
\hline 3. Perceived usability & $.771 * *$ & $.595 * *$ & 1 & & \\
\hline 4. User support & $.588 * *$ & $.745 * *$ & $.689 * *$ & 1 & \\
\hline 5.User satisfaction for eHRM & $.675^{* *}$ & $.771 * *$ & $.591 * *$ & $.761 * *$ & 1 \\
\hline
\end{tabular}

$$
* * \mathrm{p}<0.01
$$

The $t$ test was used to define whether HR personnel's perceptions towards eHRM show difference or not along with position variable. Therefore the results show a difference which was statistically significant between these two variables (p: $0.007<0.05$ ). So, H1a is an accepted hypothesis.

So, it is observed that the perception of HR staff working as top-level HR managers, mid-level HR managers, and low-level HR managers are different. As per the results (top-level HR managers 3.92, mid-level HR managers 3.67, low-level HR managers 3.03), the perception towards of top-level HR managers and mid-level HR managers are significantly altered and significant from the perceptions of low-level HR managers.

Table 4: Summary of one-way ANOVA for Perception towards eHRM

\begin{tabular}{lllllll}
\hline & & $\begin{array}{l}\text { Sum of } \\
\text { squares (SS) }\end{array}$ & df & $\begin{array}{l}\text { Mean } \\
\text { Square }\end{array}$ & F & Significance \\
\hline $\begin{array}{l}\text { Perception } \\
\text { towards eHRM }\end{array}$ & $\begin{array}{l}\text { Between } \\
\text { Groups }\end{array}$ & 5.786 & 3 & 1.929 & 6.123 & .009 \\
& Within Groups & 32.674 & 56 & .584 & \\
\hline
\end{tabular}

After that, to detect whether or not HR personnel's satisfaction from eHRM shows difference along with their position, one-way ANOVA test was utilized. The analysis indicates statistically significant difference between 2 
variables (p: $0.028<0.05$ ). So, H1b is an accepted hypothesis.

The results also show that the satisfaction of HR personnel as top-level HR managers, mid-level HR managers, and low-level HR managers are different. Table 5 indicates that as per the results (top-level HR managers 3.87, mid-level HR managers 3.61, low-level HR managers 3.10), the eHRM satisfaction of HR executives/ senior HR executives and HR manager are statistically altered and significantly from the satisfaction of HR officers/senior HR officers.

Table 5: one-way ANOVA results for eHRM satisfaction

\begin{tabular}{ccccccc}
\hline & $\begin{array}{l}\text { Sum of } \\
\text { Squares }\end{array}$ & df & $\begin{array}{c}\text { Mean } \\
\text { Square }\end{array}$ & F & Sig. \\
\hline $\begin{array}{c}\text { BHRM } \\
\text { satisfaction }\end{array}$ & $\begin{array}{c}\text { Getween } \\
\text { Within } \\
\text { Groups }\end{array}$ & 5.988 & 3 & 1.996 & 4.189 & .028 \\
\hline & 43.781 & 56 & .781 & & \\
\hline
\end{tabular}

Table 6: summary of research hypothesizes

\begin{tabular}{llc}
\hline \multicolumn{1}{c}{ Hypothesis } & p-value & Result \\
\hline $\begin{array}{l}\text { H1: There is a link between HR personnel's satisfaction for eHRM and HR } \\
\text { personnel's perceptions towards eHRM }\end{array}$ & .000 & Accepted \\
\hline $\begin{array}{l}\text { H1a: HR personnel's perceptions towards eHRM show difference along with their job } \\
\text { position. }\end{array}$ & .009 & Accepted \\
\hline $\begin{array}{l}\text { H1b: HR personnel's satisfaction for eHRM shows difference along with their job } \\
\text { position. }\end{array}$ & .028 & Accepted \\
\hline $\begin{array}{l}\text { H1c: HR personnel's perceptions towards eHRM show difference along with their } \\
\text { genders. }\end{array}$ & .189 & Rejected \\
\hline $\begin{array}{l}\text { H1d: HR personnel's satisfaction for eHRM shows difference along with their } \\
\text { genders. }\end{array}$ & .231 & Rejected \\
\hline $\begin{array}{l}\text { H1e: HR personnel's perceptions towards eHRM show difference along with their } \\
\text { education levels. }\end{array}$ & .786 & Rejected \\
\hline $\begin{array}{l}\text { H1f: HR personnel's satisfaction for eHRM shows difference along with their } \\
\text { education levels. }\end{array}$ & .453 & Rejected \\
\hline $\begin{array}{l}\text { H1g: HR personnel's perceptions towards eHRM show difference along with their } \\
\text { ages. }\end{array}$ & .099 \\
\hline $\begin{array}{l}\text { H1h: HR personnel's satisfaction for eHRM shows difference along with their ages. } \\
\text { Rejected }\end{array}$ & .179 & Rejected \\
\hline
\end{tabular}

In this study, t-test and one-way ANOVA test were applied to detect whether or not perception of eHRM and satisfaction from eHRM show difference along with gender, education and age variables. Table 6 indicates no statistically strong difference was between gender, education and age. The summary of all hypothesizes are shown above.

Yuslizaa and Ramayah (2012) surveyed on 154 HR professionals to extract the factors that can affect attitude towards eHRM. They found employee attitude had an excellent relationship with clarity of eHRM goals, perceived usability, perceived usefulness, user support, user satisfaction for eHRM, social influence and facilitating conditions. Recently, Bal et al. (2013) revealed a relationship between employee satisfaction for eHRM and HR personnel's perceptions of eHRM in Turkey firms. So, this research also explored the same directions. 


\section{Conclusion and recommendations}

In this study, HR personnel's satisfaction for eHRM usage and HR personnel's perceptions towards eHRM were examined. Among all dimensions selected for eHRM such as software quality, information quality, perceived usability, and user support for eHRM have positive and very significant relationship according to correlation analysis. The results also found no relation between demographic variables (gender, age, and education level) and perception towards as well as eHRM satisfaction in usage. The results of the study disclose that HR personnel perceive eHRM as useful and adequate user supportive; so HR personnel are satisfied with the eHRM. It was also found that both HR personnel's satisfaction and perception towards eHRM indicate difference along with position variable.

The eventual outcomes of the exploration could be generalized for different nations such as in Latin America, South East Asia, North Africa, and Middle East. This may work with more profound bits of knowledge in regards to the adaption of advanced technology and the utilization for the firms. With larger sample size Longitudinal study can be adopted for further analysis. Other research approaches and be employed that include case studies to provide inclusive insights in the future.

\section{REFERENCES}

Armstrong, B., Fogarty, G. J., Dingsdag, D. \& Dimbleby, J. 2005. Validation of a Computer User Satisfaction Questionnaire to Measure IS Success in Small Business. Journal of Research and Practice in Information Technology, 37, 27-42.

Ashraf, M. A., Tawhid, A. A. M., Masum, A. K. M., Al Abid, F. B., Ahmed, S. A., \& Khan, S. I. 2019. December). Performance Evaluation of IT Professionals Based on Fuzzy-AHP and DEMATEL Models: Bangladesh Perspective. In 2019 22nd International Conference on Computer and Information Technology (ICCIT) (pp. 1-5). IEEE.

Alam, M. G. R., Masum, A. K. M., Beh, L. S., \& Hong, C. S. 2016. Critical factors influencing decision to adopt human resource information system (HRIS) in hospitals. PloS one, 11(8), e0160366.

Bal, Y., Bozkurt, S. \& Ertemsir, E. 2013. The Importance of Using Human Resources Information Systems (HRIS) and a Research on Determining the Success of HRIS. In: Tiwari, M. D., Tiwari, I. \& Shah, S. (Eds.) Strategic Human Resource Management at Tertiary Level. Aalborg, Denmark: River Publishers.

Beckers, A. M. \& Bsat, M. Z. 2002. A DSS Classification Model for Research in Human Resource Information Systems. Information Systems Management, 19, 41-50.

Bhuiyan, M. R. U. \& Rahman, M. R. Application of Human Resource Information System in the Firms of Bangladesh and its Strategic Importance. Proceedings of Annual Paris Business and Social Science Research Conference, 2013. 4-5.

Bondarouk, T. \& Ruël, H. 2009. Electronic Human Resource Management: Challenges in the Digital Era. The International Journal of Human Resource Management, 20, 505-514.

Bondarouk, T., Ruel, H. \& Van Der Heijden, B. 2009. E-HRM Effectiveness in a Public Sector Organization: A Multi-Stakeholder Perspective. The International Journal of Human Resource Management, 20, 578-590.

Brown, S. A., Massey, A. P., Montoya-Weiss, M. M. and Burkman, J. R. (2002). Do I Really have to? User Acceptance of Mandated Technology. European Journal of Information Systems, 11(4), 283-295.

Chowdhury, M. S. A., Yunus, M., Bhuiyan, F. \& Kabir, M. R. 2013. Impact of Human Resources Information System (HRIS) on the Performance of Firms: A Study on Some Selected Bangladeshi Banks. $9^{\text {th }}$ Asian Business Research Conference Biam Foundation, Dhaka, Bangladesh.

Davis, F. D. 1989. Perceived Usefulness, Perceived Ease of Use and User Acceptance of Information Technology. MIS Quarterly 13, 319-340.

Doll, W. J. \& Torkzadeh, G. 1988. The Measurement of End-User Computing Satisfaction. MIS Quarterly, 12, 259-274.

Ferdous, F., Chowdhury, M. M. \& Bhuiyan, F. 2015. Barriers to the Implementation of Human Resource Information Systems. Asian Journal of Management Sciences \& Education, 4, 33-42.

Gliem, J. A. \& Gliem, R. R. Calculating, Interpreting, and Reporting Cronbach's Alpha Reliability Coefficient for Likert-Type Scales. 2003. Midwest Research-to-Practice Conference in Adult, Continuing, and 
Community Education.

Ibrahim, H. \& Yusoff, Y. M. 2015. User Characteristics as Antecedents of Techno Stress Towards E-HRM: From Experts' Views. Procedia-Social and Behavioral Sciences, 172, 134-141.

Islam, S., \& Al Mamun, M. A. (2016). Perception of management on outcomes of human resource information system (HRIS). International Journal of Business and Social Research, 6, 29-37.

Lawler, E. E. \& Mohrman, S. A. 2003. HR as a Strategic Partner: What Does It Take to Make It Happen? Human Resource Planning, 26, 15-29.

Lin, H.-F. \& Lee, G.-G. 2006. Determinants of Success for Online Communities: An Empirical Study. Behaviour and Information Technology, 25, 479-488.

Lukaszewski, K. M., Stone, D. L. \& Stone-Romero, E. F. 2008. The Effects of the Ability to Choose the Type of Human Resources System on Perceptions of Invasion of Privacy and System Satisfaction. Journal of Business and Psychology, 23, 73-86.

Maier, C., Laumer, S., Eckhardt, A. \& Weitzel, T. 2013. Analyzing The Impact of HRIS Implementations on HR Personnel's Job Satisfaction and Turnover Intention. The Journal of Strategic Information Systems, 22, 193-207.

Masum, A. K. M. 2015. Adoption Factors of Electronic Human Resource Management (E-HRM) in Banking Industry of Bangladesh. Journal of Social Sciences, 11, 1-10.

Masum, A. K. M., Bhuiyan, F. \& Kabir, R. 2013. HRIS Practices in Universities: An Exploratory Study on the Private Universities in Bangladesh. Global Journal of Human-Social Science Research, 13, 25-29.

Masum, A. K. M., Kabir, M. J. \& Chowdhury, M. M. 2015. Determinants that Influencing the Adoption Of EHRM: An Empirical Study on Bangladesh. Asian Social Science, 11, P117.

Masum, A. K. M., Abid, F. B., Arafat, A. Y., \& Beh, L. S. 2020. Factors Influencing Practice of Human Resource Information System in Organizations: A Hybrid Approach of AHP and DEMATEL. International Journal of Advanced Computer Science and Applications,, 11 (6), p701-706

Masum A. K. M., Mamun, A. M. A., Islam, M. S. and Beh, L.S. 2020. The Impact of eHRM Practice on Organizational Performance: Investigating the Effect of Job Satisfaction of HRM Professionals. Journal of Computer Science, 16(7), 983-1000.

Masum, A. K. M., Beh, L. S., Azad, M. A. K., \& Hoque, K. 2018. Intelligent human resource information system (i-HRIS): a holistic decision support framework for HR excellence. Int. Arab J. Inf. Technol., 15(1), 121130.

Ngai, E. \& Wat, F. 2006. Human Resource Information Systems: A Review and Empirical Analysis. Personnel Review, 35, 297-314.

Ngai, E. W. T., Law, C. C. H., Chan, S. C. H. \& Wat, F. K. T. 2008. Importance of the internet to Human Resource Practitioners in Hong Kong. Personnel Review, 37, 66-84.

Panayotopoulou, L., Vakola, M. \& Galanaki, E. 2007. E-HR Adoption and the Role of HRM: Evidence from Greece. Personnel Review, 36, 277-294.

Stone, D. L., Deadrick, D. L., Lukaszewski, K. M. \& Johnson, R. 2015. The Influence of Technology on the Future of Human Resource Management. Human Resource Management Review, 25, 216-231.

Stone, D. L. \& Lukaszewski, K. 2009. An Expanded Model of the Factors Affecting the Acceptance and Effectiveness of Electronic Human Resource Management Systems. Human Resource Management Review, 19, 134-143.

Strohmeier, S. 2009. Concepts Of E-Hrm Consequences: A Categorisation, Review and Suggestion. The International Journal of Human Resource Management, 20, 528-543.

Taylor, S. P. \& Todd, P. A. 1995. Understanding Information Technology Usage: A Test of Competing Models. Information Systems Research, 6, 144-176.

Vandenberghe, C., Panaccio, A., Bentein, K., Mignonac, K. \& Roussel, P. 2011. Assessing Longitudinal Change of and Dynamic Relationships among Role Stressors, Job Attitudes, Turnover Intention, and Well-being in Neophyte Newcomers. Journal of Organizational Behavior, 32, 652-671.

Voermans, M. \& Van Veldhoven, M. 2007. Attitude towards E-HRM: An Empirical Study at Philips. Personnel 
Review, 36, 887-902.

Wang, Y. S. 2008. Assessing E-Commerce Systems Success: A Respecification and Validation of the Delone and Mclean Model of IS Success. Information Systems Journal, 18, 529-557.

Wiblen, S., Grant, D. \& Dery, K. 2010. Transitioning to a New HRIS: The Reshaping of Human Resources and Information Technology Talent. Journal of Electronic Commerce Research, 11, 251-267.

Wright, C. 2008. Reinventing Human Resource Management: Business Partners, Internal Consultants and the Limits to Professionalization. Human Relations, 61, 1063-1086.

Yuslizaa, M. \& Ramayah, T. 2012. Determinants of Attitude towards E-HRM: An Empirical Study Among HR Professionals. Procedia-Social and Behavioral Sciences, 57, 312-319. 